\title{
Optimization of Reconfigurable Manufacturing Systems Configuration: A Literature Review
}

\author{
Rachel Campos Sabioni $\left.{ }^{(}\right)$, Joanna Daaboul, and Julien Le Duigou \\ Université de Technologie de Compiègne, CNRS, Roberval (Mechanics Energy and Electricity), \\ Centre de recherche Royallieu - CS 60319 - 60 203, Compiègne Cedex, France \\ rachel.campos-sabioni@utc.fr
}

\begin{abstract}
Reconfigurable Manufacturing Systems (RMS) have gained importance in the current context of increasing high variety demand, Mass Customization (MC) and market instability, due to their ability of being quickly modified to adjust their production capacity to attain sudden fluctuations in market demands as well as to accommodate operations of new products. RMS can be configured at system and machine levels. Many papers have described the RMS configuration as combinatorial optimization problems and proposed several techniques to optimize them in terms of different responses of interest. This paper presents a literature review that seeks to understand how RMS configuration has been addressed in terms of configuration level, optimization problem modelling and techniques applied to solve it. This work aims to assist researchers working on RMS configuration to identify trends and new research opportunities.
\end{abstract}

Keywords: Reconfigurable Manufacturing Systems · System configuration · Optimization $\cdot$ Layout design $\cdot$ Machine selection $\cdot$ Machine configuration

\section{Introduction}

Increased demand for high variety and mass-customized products forces companies to increase their flexibility throughout their value chain, which can be achieved in manufacturing via Reconfigurable Manufacturing Systems (RMS). RMS are designed to be rapidly modified to adjust their production capacity and functionality, for responding to abrupt variations on market demands [1]. To achieve that, RMS count with Computer Numerically Controlled (CNC) machines, and Reconfigurable Machine Tools (RMT), which are modular machines capable to be configured in different ways for performing specific operations $[2,3]$.

RMS configuration can be divided into system and machine levels [4]. While systemlevel configuration is related to the layout design, the machine-level corresponds to change or adjust auxiliary machine-modules [5]. Both configuration levels require supplementary costs during the production process that cannot be neglected $[6,7]$. Many researchers have proposed different methods to optimize the RMS configuration, considering system or machine-level independently or jointly. 
However, as far as we know, there is still no paper focused on understanding optimization issues of RMS configuration. To fill this gap, this paper presents a literature review to investigate (1) How RMS configuration optimization problems are modelled, (2) Which are the main methods used to solve them and (3) Which are the main focus of papers when optimizing the RMS configuration in terms of: (a) configuration-level, (b) objective function and (c) process/production planning.

This review was conducted in four databases: SCOPUS, Science Direct, ISI Web of Science and Taylor \& Francis with the keywords "Reconfigurable Manufacturing System" AND "configuration". The 924 papers found were screened in order to filter only journal papers from 2009 to 2020, and to remove all duplicates and papers not written in English or without the full text available. Finally, 54 papers were selected. This paper is organized as follows. Section 2 brings a broad overview of papers found in literature and Sect. 3 presents the conclusion.

\section{Overview of RMS Configuration Optimization Papers}

\subsection{Main Focus of Papers Optimizing the RMS Configuration}

Table 1 presents the configuration levels addressed by papers optimizing the RMS configuration, which are divided in three main types: (1) system and machine levels jointly $(68.5 \%),(2)$ system-level (26\%) and (3) machine-level (5.5\%).

Table 1. Configuration-level addressed by papers optimizing the RMS configuration.

\begin{tabular}{l|l|l|l}
\hline \multicolumn{2}{l|}{$\begin{array}{l}\text { Config. level } \\
\text { System and machine } \\
\text { level }\end{array}$} & $\begin{array}{l}\text { Characteristics } \\
\text { System configuration is related to machine addition } \\
\text { or removal. Further, each machine can be } \\
\text { reconfigured by changing its auxiliary-modules or } \\
\text { tools }\end{array}$ & [2-7, 22-52] \\
\hline System level & $\begin{array}{l}\text { Layout } \\
\text { design }\end{array}$ & $\begin{array}{l}\text { System configuration is based on machines selection } \\
\text { and their position in layout. Machine-configuration } \\
\text { is not addressed }\end{array}$ & {$[15-21]$} \\
\hline & - & $\begin{array}{l}\text { System configuration is based on the operations path } \\
\text { or on adding/removing machines from the system. } \\
\text { There is no reference to layout design issues }\end{array}$ & {$[8-14]$} \\
\hline Machine configuration & $\begin{array}{l}\text { Configuration of a machine singly to produce a } \\
\text { specific product or product family }\end{array}$ & {$[53-55]$} \\
\hline
\end{tabular}

However, machine configuration as well as its layout placement could highly affect manufacturing costs. Therefore, layout design and machine configuration must be considered together in the RMS configuration for process planning (PP) or production planning (ProP). Few papers worked on the RMS configuration to improve their PP $(21.1 \%)$. PP is the translation of a single product design data into a method to manufacture it, including machine and configuration selection and operations sequencing [29]. 
This is why PP papers mainly worked with a single product $[11,16,19,43]$. ProP was the mainly focus of the most part of papers addressing the RMS configuration (78.9\%). ProP assigns operations defined by PP while respecting some constraints such as due time, machine capacity etc. and generally includes the plan of multiple parts/products simultaneously $[3,10]$. In fact, ProP papers from this review mostly optimized the RMS configuration for one or many product families and multiple product/parts simultaneously, by respecting machine capacity and specific demand rates in a time period [15, 24, 29, 40].

Since RMS is a relatively new type of production system, it is still hard to find completely reconfigurable systems in industries; hampering the implementation of real case studies. Papers mainly conducted case studies through numerical illustration or simulation $(83 \%)$. They mainly used simple or generic parts (few features) and hypothetical values for required parameters (e.g. machine allocation and configuration cost) $[3,6$, $7,44]$. This not exactly represents the real life, since modular products can be much more complex, especially in high variety context. Hence, more research with complex products (many features) is still required.

Papers applying real case studies (17\%) mostly used a work-piece provided by an industrial partner to map required operations and, based on that, identify all machineconfigurations capable to execute these operations. Although their propositions were focused on RMS, their case studies were usually applied in process composed by CNC or dedicated machines, without including RMTs [17, 23, 24, 53]. Some researchers conducted their case study in a reconfigurable assembly line of an automotive industry $[10,25]$; while others did not clearly present the machine types that made up their case study $[8,11,15]$.

\subsection{Modelling and Optimizing the RMS Configuration}

Optimization problems of RMS configuration found in literature were mainly multivariate and multi-objective. This confirms the complexity of optimizing RMS configuration, since researchers must consider many decision variables whilst optimizing various responses of interest. Table 2 summarizes the techniques used to model and solve these problems. They were mainly modelled with integer variables varying between nonlinear and linear models, with the predominance of the latter.

Nonlinear problems were mostly solved by approximate or hybrid approaches using GA singly [13, 17, 50, 52] or coupled with other methods, like Monte Carlo [30] and dynamic programming [42]. Linear problems were also solved by approximate methods, but papers mostly tried to validate a new heuristic [43] or metaheuristic method [44, 54] by comparing their solution with those obtained by the well-known NSGA-II. Since commercial software, like LINGO, are capable to find a global optimum for ILP and MILP problems, some papers compared their results with those obtained by approximate $[5,53,54]$ or hybrid methods [51] to verify the reliability of those methods. Others just used these solvers singly [28, 47, 48]. Linear problems were also solved by different exact approaches, like enumerative [2, 24] and iterative techniques [11, 41, 44]. 
Some papers modelled their problems as Multi-Criteria Decision-Making (MCDM) ones, by comparing divergent criteria of multiple alternatives and ranking them according to its suitability. MCDM problems mainly compared different system configurations [21, 55], but comparison of resource [16] and scheduling [25] alternatives were also found. They mainly addressed qualitative attributes (e.g. system reconfigurability, convertibility) being mostly solved by heuristic $[16,21,25]$ or enumerative methods $[34,55]$.

Many papers from literature partially detailed their optimization problems, without including all information about decision variables, constraints etc., while others presented the whole model without classifying their problem [23, 38, 39, 45]. Not surprisingly, they mostly used metaheuristics (50\%), like GA and NSGA-II, which have proven their effectiveness to solve optimization problems related to RMS configuration. Metaheuristics are known to not being problem-specific, meaning that they can solve several problems with few modifications in the algorithm [56]. Therefore, it allows people solving complex problems, like RMS configuration, even if they do not totally know how to model their optimization problems. Further, papers dealing with multi-objective problems also hybridized multi-objective metaheuristics, like NSGA-II and AMOSA, with TOPSIS, which attributes weights to each objective for ranking solutions in the Pareto front $[3,6,22]$.

Researchers tried to optimize many objectives, but cost stood out as the most addressed, being minimized by $74.1 \%$ of works. The three main types of costs were: (1) Capital cost: to attain new market demands [17, 23], to satisfy pre-fixed demand scenarios [2, 27, 33], or to deal with stochastic demands [13, 14]. (2) Reconfiguration cost: mainly related to machine allocation or configuration for reducing costs of changing product's production within the same family [32, 36, 37]. (3) Production cost: of single/multiple parts $[3,44,53]$. Most of the time, papers addressed the minimization of these costs simultaneously [3, 5-7,36].

Due to the RMS ability to rapidly change their production capacity or to accommodate new operations required by new product launches, they are known as key enablers of MC. Nevertheless, few papers $(16,7 \%)$ have addressed MC, and those who have considered it mostly focused on optimizing the RMS for responding to given demand scenarios and due times [5, 10, 21, 49, 50,52]. One paper focused on increasing system modularity to accommodate high variety in $\mathrm{MC}$ [6], while others cited MC without clearly explain which were their scientific contribution to enable MC throughout the RMS configuration optimization [19, 44].

The increasing attention to the worldwide environmental sustainability have reflected the challenges faced by works optimizing the RMS configuration. Recent publications have showed their interest in minimizing the energy consumption of RMS [18, 24, 44, 54]. However, these works represent only $7.4 \%$ of papers found, meaning that there are opportunities to do more investigations in this domain. 


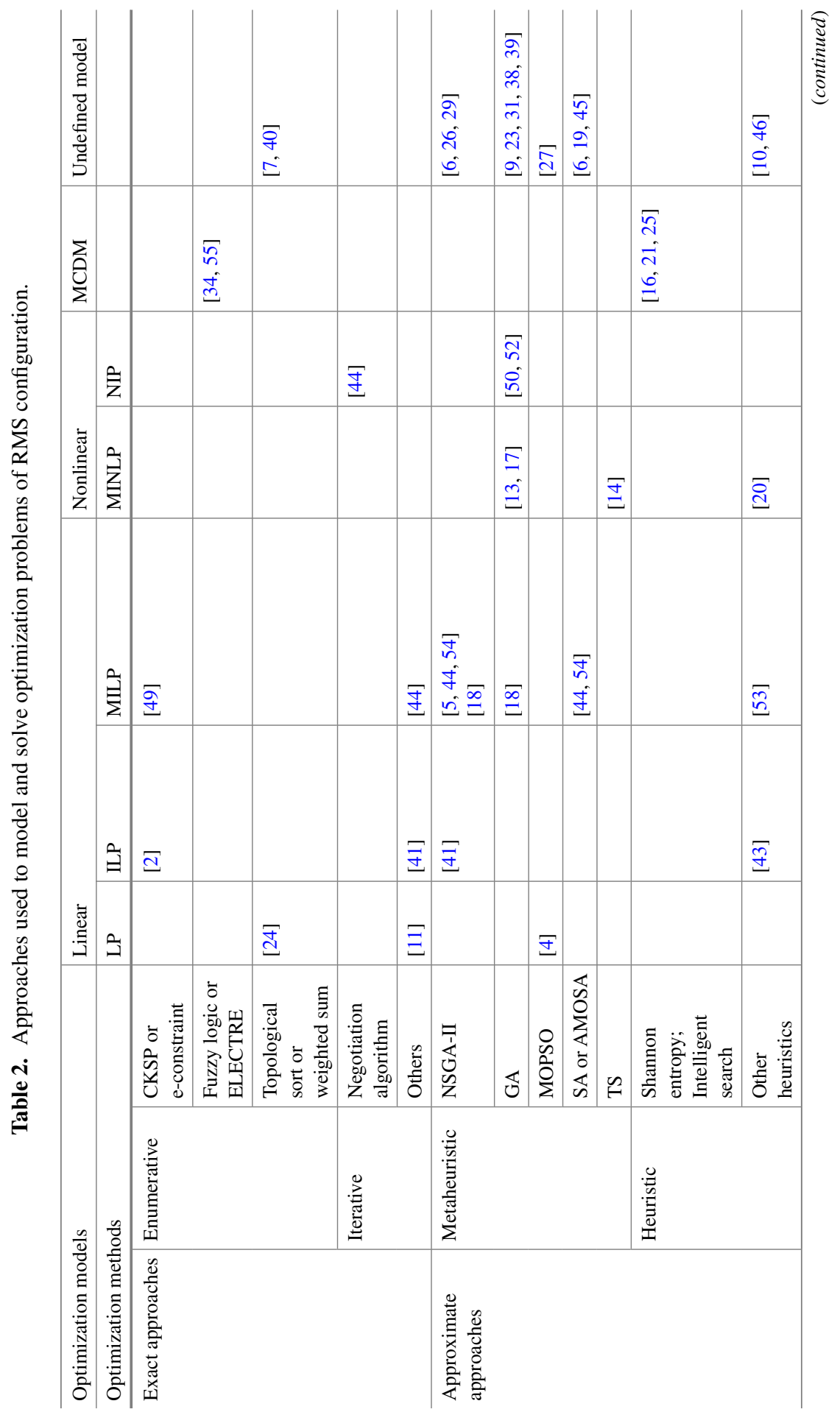




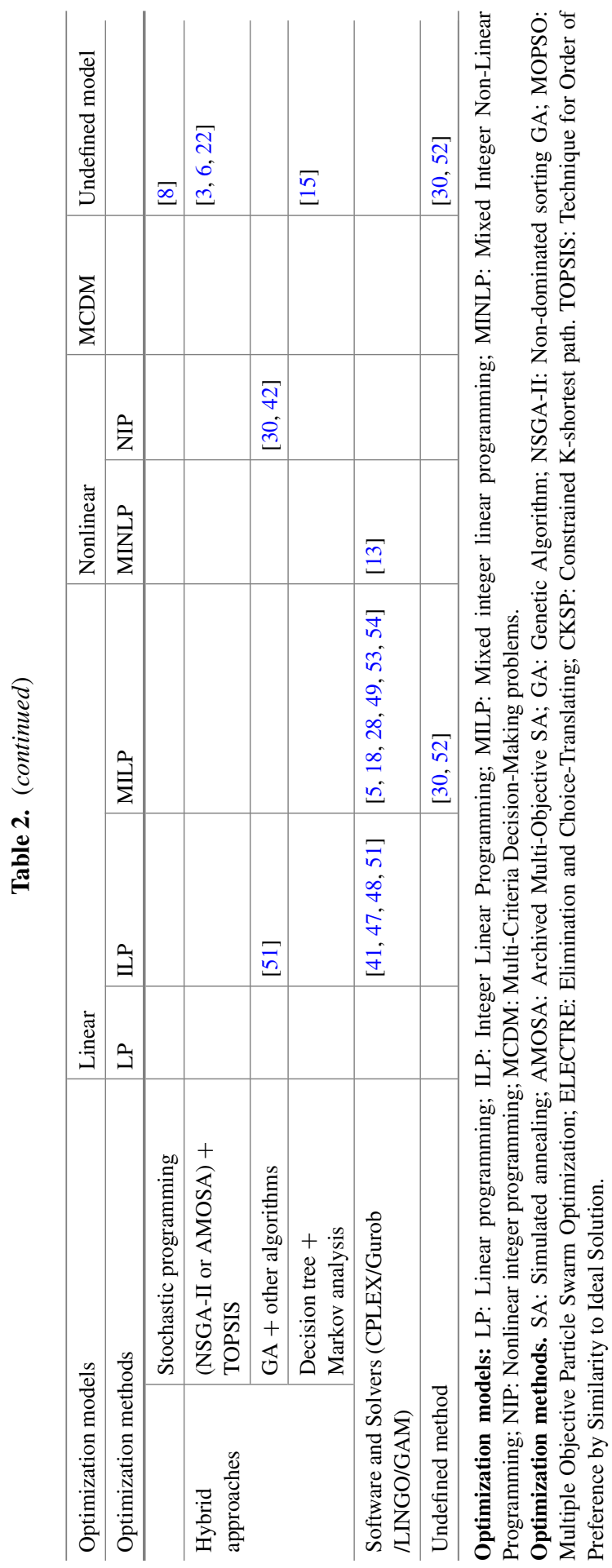




\section{Conclusion}

This paper presents a literature review of RMS configuration in terms of (1) configuration level and (2) optimization techniques for modelling and solving problems related to the RMS configuration as well as (3) the main focus of RMS configuration optimization. This review highlights that although papers mostly work with system and machine level configurations, there is still no work dealing with layout design and machineconfiguration issues simultaneously. Indeed, few papers were dedicated to the layout design optimization. Very few papers conducted real case studies and those who have done it did not address RMTs, evidencing that it is still very hard to find laboratories or industries equipped with RMS or their prototypes. RMS configuration optimization problems are mainly modelled with integer variables or no optimization model is available. In any case, metaheuristic methods highlight as the most used ones due to their ability of solving complex optimization problems by providing optimal acceptable solutions in relatively little time. Cost minimization is the main focus of papers optimizing the RMS configuration; however, recent publications also show a tendency to focus on sustainability and MC issues.

Acknowledgments. This work was supported by the French National Research Agency under Grant ANR-17-CE10-0010-01.

\section{References}

1. Koren, Y., et al.: Reconfigurable manufacturing systems. CIRP Annal. Manufact. Technol. 48(2), 527-540 (1999)

2. Dou, J., Dai, X., Meng, Z.: Graph theory-based approach to optimize single-product flow-line configurations of RMS. Int. J. Adv. Manufact. Technol. 41(9-10), 916-931 (2009)

3. Goyal, K.K., Jain, P.K., Jain, M.: Optimal configuration selection for reconfigurable manufacturing system using NSGA II and TOPSIS. Int. J. Prod. Res. 50(15), 4175-4191 (2012)

4. Goyal, K.K., Jain, P.K.: Design of reconfigurable flow lines using MOPSO and maximum deviation theory. Int. J. Adv. Manufact. Technol. 84(5-8), 1587-1600 (2016)

5. Dou, J., Li, J., Su, C.: Bi-objective optimization of integrating configuration generation and scheduling for reconfigurable flow lines using NSGA-II. Int. J. Adv. Manufact. Technol. 86(5-8), 1945-1962 (2016)

6. Benderbal, H.H., Dahane, M., Benyoucef, L.: Modularity assessment in reconfigurable manufacturing system (RMS) design: an archived multi-objective simulated annealing-based approach. Int. J. Adv. Manufact. Technol. 94, 729-749 (2018)

7. Saxena, L.K., Jain, P.K.: A model and optimisation approach for reconfigurable manufacturing system configuration design. Int. J. Prod. Res. 50(12), 3359-3381 (2012)

8. Copani, G., Urgo, M.: Innovative flexibility-oriented business models and system configuration approaches: an industrial application. CIRP J. Manufact. Sci. Technol. 11, 10-17 (2015)

9. Xiaowen, X., Beirong, Z., Wei, X.: Configuration optimization method of reconfigurable manufacturing systems. Res. J. Appl. Sci. Eng. Technol. 6(8), 1389-1393 (2013)

10. Pattanaik, L.N., Jena, A.: Tri-objective optimisation of mixed model reconfigurable assembly system for modular products. Int. J. Comput. Integr. Manuf. 32(1), 72-82 (2018) 
11. Lv, C., Li, A.P., Xu, L.Y.: Research and optimization of reconfigurable manufacturing system configuration based on system reliability. Kybernetes 39(6), 1058-1065 (2010)

12. Hasan, F., Jain, P.K., Kumar, D.: Optimum configuration selection in reconfigurable manufacturing system involving multiple part families. Opsearch 51(2), 297-311 (2014)

13. Abbasi, M., Houshmand, M.: Production planning and performance optimization of reconfigurable manufacturing systems using genetic algorithm. Int. J. Adv. Manufact. Technol. 54(1-4), 373-392 (2011)

14. Abbasi, M., Houshmand, M.: Production planning of reconfigurable manufacturing systems with stochastic demands using Tabu search. Int. J. Manufact. Technol. Manage. 17(1-2), 125-148 (2009)

15. Abdi, M.R., Labib, A.: RMS capacity utilisation: product family and supply chain. Int. J. Prod. Res. 55(7), 1930-1956 (2016)

16. Michalos, G., Makris, S., Mourtzis, D.: An intelligent search algorithm-based method to derive assembly line design alternatives. Int. J. Comput. Integr. Manufact. 25(3), 211-229 (2012)

17. Wang, W., Koren, Y.: Scalability planning for reconfigurable manufacturing systems. J. Manufact. Syst. 31(2), 83-91 (2012)

18. Ghanei, S., Algeddawy, T.: An integrated multi-period layout planning and scheduling model for sustainable reconfigurable manufacturing systems. J. Adv. Manufact. Syst. 19(1), 31-64 (2020)

19. Haddou Benderbal, H., Benyoucef, L.: Machine layout design problem under product family evolution in reconfigurable manufacturing environment: a two-phase-based AMOSA approach. Int. J. Adv. Manufact. Technol. 104(1-4), 375-389 (2019)

20. Guan, X., Dai, X., Qiu, B., Li, J.: A revised electromagnetism-like mechanism for layout design of reconfigurable manufacturing system. Comput. Ind. Eng. 63(1), 98-108 (2012)

21. Gupta, A., Jain, P.K., Kumar, D.: Configuration selection of reconfigurable manufacturing system based on performance. Int. J. Ind. Syst. Eng. 20(2), 209-229 (2015)

22. Benderbal, H.H., Dahane, M., Benyoucef, L.: Flexibility-based multi-objective approach for machines selection in reconfigurable manufacturing system (RMS) design under unavailability constraints. Int. J. Prod. Res. 55(20), 6033-6051 (2017)

23. Koren, Y., Wang, W., Gu, X.: Value creation through design for scalability of reconfigurable manufacturing systems. Int. J. Prod. Res. 55(5), 1227-1242 (2016)

24. Choi, Y.-C., Xirouchakis, P.: A holistic production planning approach in a reconfigurable manufacturing system with energy consumption and environmental effects. Int. J. Comput. Integr. Manuf. 28(4), 379-394 (2015)

25. Prasad, D., Jayswal, S.C.: Reconfigurability consideration and scheduling of products in a manufacturing industry. Int. J. Prod. Res. 56(19), 6430-6449 (2017)

26. Bensmaine, A., Dahane, M., Benyoucef, L.: A non-dominated sorting genetic algorithm based approach for optimal machines selection in reconfigurable manufacturing environment. Comput. Ind. Eng. 66(3), 519-524 (2013)

27. Goyal, K.K., Jain, P.K., Jain, M.: Applying Swarm intelligence to design the reconfigurable flow lines. Int. J. Simul. Model. 12(1), 17-26 (2013)

28. Eguia, I., Molina, J.C., Lozano, S., Racero, J.: Cell design and multi-period machine loading in cellular reconfigurable manufacturing systems with alternative routing. Int. J. Prod. Res. 55(10), 2775-2790 (2017)

29. Mohapatra, P., Benyoucef, L., Tiwari, M.K.: Integration of process planning and scheduling through adaptive setup planning: a multi-objective approach. Int. J. Prod. Res. 51(23-24), 7190-7280 (2013)

30. Renna, P.: A decision investment model to design manufacturing systems based on a genetic algorithm and Monte-Carlo simulation. Int. J. Comput. Integr. Manuf. 30(6), 590-605 (2016) 
31. Asghar, E., Zaman, U.K., Baqai, A.A., Homri, L.: Optimum machine capabilities for reconfigurable manufacturing systems. Int. J. Adv. Manufact. Technol. 95(9-12), 4397-4417 (2018)

32. Mittal, K.K., Kumar, D., Jain, P.K.: a systematic approach for optimum configuration selection in reconfigurable manufacturing system. J. Inst. Eng. India Ser. C 99(6), 629-635 (2018)

33. Gupta, A., Jain, P.K., Kumar, D.: A novel approach for part family formation for reconfiguration manufacturing system. Opsearch 51(1), 76-97 (2014)

34. Rehman, A.U., Babu, A.S.: The evaluation of manufacturing systems using concordance and disconcordance properties. Int. J. Serv. Oper. Manage. 5(3), 326-349 (2009)

35. Li, X., Bayrak, A.E., Epureanu, B.I., Koren, Y.: Real-time teaming of multiple reconfigurable manufacturing systems. CIRP Annal. Manufact. Technol. 67(1), 437-440 (2018)

36. Ashraf, M., Hasan, F.: Configuration selection for a reconfigurable manufacturing flow line involving part production with operation constraints. Int. J. Adv. Manufact. Technol. 98(5-8), 2137-2156 (2018)

37. Moghaddam, S.K., Houshmand, M., Valilai, O.F.: Configuration design in scalable reconfigurable manufacturing systems (RMS); a case of single-product flow line (SPFL). Int. J. Prod. Res. 56(11), 3932-3954 (2018)

38. Vafadar, A., Hayward, K., Tolouei-Rad, M.: Drilling reconfigurable machine tool selection and process parameters optimization as a function of product demand. J. Manufact. Syst. 45, 58-69 (2017)

39. Xie, N., Li, A., Xue, W.: Cooperative optimization of reconfigurable machine tool configurations and production process plan. Chin. J. Mech. Eng. (English Edn.) 25(5), 982-989 (2012)

40. Mittal, K.K., Jain, P.K., Kumar, D.: Configuration selection in reconfigurable manufacturing system based on reconfigurability. Int. J. Logist. Syst. Manage. 27(3), 363 (2017)

41. Yu, J.M., Doh, H.H., Kim, H.W., Kim, J.S., Lee, D.H., Nam, S.H.: Iterative algorithms for part grouping and loading in cellular reconfigurable manufacturing systems. J. Oper. Res. Soc. 63(12), 1635-1644 (2012)

42. Bryan, A., Hu, S.J., Koren, Y.: Assembly system reconfiguration planning. J. Manuf. Sci. Eng. 135(4), 041005 (2013)

43. Touzout, F.A., Benyoucef, L.: Multi-objective multi-unit process plan generation in a reconfigurable manufacturing environment: a comparative study of three hybrid metaheuristics. Int. J. Prod. Res. 57(24), 7520-7535 (2019)

44. Touzout, F.A., Benyoucef, L.: Multi-objective sustainable process plan generation in a reconfigurable manufacturing environment: exact and adapted evolutionary approaches. Int. J. Prod. Res. 57(8), 2531-2547 (2019)

45. Musharavati, F., Hamouda, A.S.M.: Enhanced simulated-annealing-based algorithms and their applications to process planning in reconfigurable manufacturing systems. Adv. Eng. Softw. 45(1), 80-90 (2012)

46. Zhang, L., Rodrigues, B.: Modelling reconfigurable manufacturing systems with coloured timed Petri nets. Int. J. Prod. Res. 47(16), 4569-4591 (2009)

47. Moghaddam, S.K., Houshmand, M., Saitou, K., Fatahi Valilai, O.: Configuration design of scalable reconfigurable manufacturing systems for part family. Int. J. Prod. Res. 58, 2974 2996 (2019)

48. Bortolini, M., Galizia, F.G., Mora, C., Pilati, F.: Reconfigurability in cellular manufacturing systems: a design model and multi-scenario analysis. Int. J. Adv. Manufact. Technol. 104(912), 4387-4397 (2019)

49. Dou, J., Su, C., Zhao, X.: Mixed integer programming models for concurrent configuration design and scheduling in a reconfigurable manufacturing system. Concurr. Eng. Res. Appl. 28(1), 32-46 (2020) 
50. Dou, J., Dai, X., Meng, Z.: Optimisation for multi-part flow-line configuration of reconfigurable manufacturing system using GA. Int. J. Prod. Res. 48(14), 4071-4100 (2010)

51. Dou, J., Dai, X., Meng, Z.: Precedence graph-oriented approach to optimise single-product flow-line configurations of reconfigurable manufacturing system. Int. J. Comput. Integr. Manuf. 22(10), 923-940 (2009)

52. Dou, J., Dai, X., Meng, Z.: A GA-based approach for optimizing single-part flow-line configurations of RMS. J. Intell. Manufact. 22(2), 301-317 (2011)

53. Battaïa, O., Dolgui, A., Guschinsky, N.: Decision support for design of reconfigurable rotary machining systems for family part production. Int. J. Prod. Res. 55(5), 1368-1385 (2017)

54. Liu, M., An, L., Zhang, J., Chu, F., Chu, C.: Energy-oriented bi-objective optimisation for a multi-module reconfigurable manufacturing system. Int. J. Prod. Res. 57(19), 5974-5995 (2019)

55. Mpofu, K., Tlale, N.S.: Multi-level decision making in reconfigurable machining systems using fuzzy logic. J. Manufact. Syst. 31(2), 103-112 (2012)

56. Blum, C., Roli, A.: Metaheuristics in combinatorial optimization: overview and conceptual comparison. ACM Comput. Surv. 35(3), 268-308 (2003)

Open Access This chapter is licensed under the terms of the Creative Commons Attribution 4.0 International License (http://creativecommons.org/licenses/by/4.0/), which permits use, sharing, adaptation, distribution and reproduction in any medium or format, as long as you give appropriate credit to the original author(s) and the source, provide a link to the Creative Commons license and indicate if changes were made.

The images or other third party material in this chapter are included in the chapter's Creative Commons license, unless indicated otherwise in a credit line to the material. If material is not included in the chapter's Creative Commons license and your intended use is not permitted by statutory regulation or exceeds the permitted use, you will need to obtain permission directly from the copyright holder.

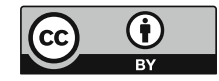

